Int. Agrophys., 2021, 35, 301-306

INTERNATIONAL

\title{
Impact of lime application on erosive strength and bulk density of aggregates**
}

\author{
Tina Frank@*, Iris Zimmermann ${ }^{(}$, and Rainer Horn $®$ \\ Soil Science, Institute of Plant Nutrition and Soil Science, Hermann-Rodewald-Str. 2, 24118 Kiel, Germany \\ Received August 10, 2021; accepted November 6, 2021
}

\begin{abstract}
An area with well-aggregated and structured soil with a high inter-aggregate strength is favourable for use as arable land, both to withstand mechanical stresses and for optimal plant growth. The application of lime in the form of $\mathrm{CaCO}_{3}$ can facilitate the formation of a stable soil structure. Therefore, we determined the impact of lime application on the erosive strength and density of air-dry aggregates sampled from a Haplic Gleysol with a clay content of $45 \%$. The lime was applied to the soil in the field at two different rates, resulting in the following: $36 \mathrm{dt} \mathrm{CaO}$-equivalents $\mathrm{ha}^{-1}$ and $54 \mathrm{dt} \mathrm{CaO}$-equivalents $\mathrm{ha}^{-1}$. The results show that liming significantly increased the erosive strength of aggregates. Lower densities were observed which presumably leads to an improved accessibility of the pores and the particle surfaces within the aggregates due to the application of $\mathrm{CaCO}_{3}$. Furthermore, differences between amounts of $\mathrm{C}$ and $\mathrm{N}$ were determined in the aggregate layers between the limed plots and the control plots.

Keywords: erosive strength, arable land, liming, conventional tillage
\end{abstract}

\section{INTRODUCTION}

Aggregated soils are able to withstand stresses induced by mechanical inputs to the extent of maintaining sufficient structural stability with a well-connected pore system that permits the transport of water, gas and nutrients. During mechanical load, the soil structure can bear a substantial amount of stress but if the load applied to the soil exceeds

*Corresponding author e-mail: t.frank@soils.uni-kiel.de

**This work was carried out in cooperation with TU Berlin and financially supported by the German Federal Environmental Foundation (Deutsche Bundesstiftung Umwelt DBU) (project no 33068/01 and 33068/02 - 2017-2021). the internal soil strength then the structure is disrupted, effective stresses are reduced, and the internal soil strength decreases (Horn and Fleige, 2003). On arable land, stresses induced by agricultural vehicles can affect soil structure, and if such heavy loads are applied to the soil that the aggregates are destroyed by a process of homogenization and kneading, there is only a primary pore system left. The reduced accessibility of intra-aggregate pore spaces and of the particle surfaces that occurs may also result in a loss of nutrients. Stable aggregates provide the physical protection of occluded organic matter. When macroaggregates are destroyed by tillage, this leads to the mineralization and release of nutrients that were formerly protected inside the aggregates (John et al., 2005). As a consequence, a high aggregate strength is required to achieve sustainable physical protection and the accumulation of soil nutrients (Horn, 1990; Jastrow, 1996; Six et al., 2000; Tisdall and Oades, 1982).

Mordhorst et al. (2013), Urbanek et al. (2014) and Park and Smucker (2005c) reported the presence of concentric spatial gradients of soil organic carbon within soil aggregates. The utilization of soil aggregate erosion chambers for the separation of unique concentric layers of aggregates was first introduced by Santos et al. (1997). Park and Smucker (2005a) suggested the calculation of the erosive strength of single aggregates based on the erosive forces required to remove $1 \mathrm{~g}$ of soil within $1 \mathrm{~min}$ from the surface

(C) 2021 Institute of Agrophysics, Polish Academy of Sciences 
of a soil aggregate rotating along the abrasive wall within an erosion chamber. Urbanek et al. (2014) studied soil aggregate stability under three different tillage treatments, and found that the tensile strength of soil aggregates correlated with their erosive strength, thereby suggesting that the tensile strength of an aggregate is controlled by the sum of its concentric layer strengths.

The marshland soils on the west coast in SchleswigHolstein are often called "minute soils", because of the high risk of irreversible compaction, and only short time slots of trafficability during the field season are available. "Minute soils" with very high clay contents contain mainly fine pores that can hold a lot of water but have a tendency not to release it again (Frank et al., 2020; Schroeder, 1968). In the field sites studied, it is necessary to improve the stability of the soils in order to further improve their trafficability.

Liming is a well-established management practice to decrease the acidity level in arable soils, but it can also improve soil structure development and stability (Haynes and Naidu, 1998; Holland et al., 2018; Muneer and Oades, 1989). Lime application increases the concentrations of $\mathrm{Ca}^{2+}$ ions in the soil solution, which in turn promotes aggregate formation due to the development of cation bridges, e.g. between organic material and (clay) mineral particles (Bronick and Lal, 2005) and enhances aggregate stability (Ferreira et al., 2019; Naveed et al., 2014; Wang et al., 2017). Liming supports diffusive transport processes in the soil because it supports the development of loosely bound aggregates with a coarser pore system (Becher, 1991). Diffusive transport processes in soils are the preferred form of transport, especially in the intra-aggregate pore system, they facilitate transport from the aggregate surface to the aggregate interior (Park and Smucker, 2005b) The formation of organo-mineral complexes is favoured by improved accessibility and aggregate stability is further increased over time (Peth et al., 2008; Smucker et al., 2007) which also protects the carbon inside aggregates (Wiesmeier et al., 2012).

The aim of this study was to identify the effects of topsoil lime application on aggregate stability and the distribution of carbon $(\mathrm{C})$ and nitrogen $(\mathrm{N})$ in different aggregate layers by determining the erosive strength as well as $\mathrm{pH}, \mathrm{C}$ - and $\mathrm{N}$-contents in the exterior and interior layer of the aggregates.

\section{MATERIAL AND METHODS}

The field trial was established on arable land in August 2016. The experiment included three treatments: a control with no lime $\left(\mathrm{CaCO}_{3}\right)$ application (Lime0), lime application according to the soil-specific recommendations by (VDLUFA, 2000) to achieve an optimized soil pH (Lime1), and soil-specific recommendations $\times 1.5$ (Lime1.5). The recommended $\mathrm{pH}$ level is between 5.9 and 6.7 according to VDLUFA (2000). The site is located in Barlt, in the western part of Schleswig-Holstein, close to the North Sea in Germany. The soil is a Haplic Gleysol according to IUSS Working Group WRB (2014). The topsoil $(0-30 \mathrm{~cm})$ is a silty clay with a clay content of $45 \%$ and an organic carbon content of $56 \mathrm{~g} \mathrm{~kg}^{-1}$. The lime application rates were $36 \mathrm{dt} \mathrm{CaO-equivalents} \mathrm{ha}^{-1}$ for the Lime1-treatment and $54 \mathrm{dt} \mathrm{CaO}$-equivalents $\mathrm{ha}^{-1}$ for the Lime1.5-treatment. The study area was divided into 48 individual experimental plots and every plot had a size of $6 \times 18 \mathrm{~m}$, arranged in a Randomized Complete Block Design with four replicates per treatment. The field was managed conventionally with annual tillage and mineral nitrogen fertilization (Frank et al., 2020). Sampling of the 12 undisturbed soil blocks $\left(1 \mathrm{dm}^{3}\right)$ took place in April 2019 (32 months after lime application) from the topsoil layer $(0-10 \mathrm{~cm})$ of the Lime0, Lime1 and Lime1.5 plots (Frank et al., 2020).

The aggregate erosive strength was determined using the soil aggregate erosion (SAE) chamber method (Santos et al., 1997). For this purpose, the aggregates were collected from the field blocks in the laboratory by breaking them along their weakest rupture planes. Two concentric layers of equal mass were separated through the erosion of air-dried aggregates $(\varnothing \sim 16 \mathrm{~mm})$ as described by Urbanek et al. (2014). The removed outer layer and the remaining aggregate core represent the exterior and interior properties of the aggregate (Park and Smucker, 2005a). Before and after removing the exterior (ext.) layer, the aggregate was weighed and the volume was determined with a pyknometer (Geopyc 1360, Micromeritics, Unterschleissheim, Germany). This made it possible to determine the density of the exterior (ext.) layer of the aggregate as well as that of the aggregate core representing the interior (int.) layer. The exterior layer was removed from the aggregates by rotating them at $400 \mathrm{rpm}$ in erosion chambers $(\varnothing=24 \mathrm{~mm})$ on a rotary shaker (IKA KS 260 control, Staufen, Germany) with continuous contact with the abrasive chamber walls, until the weight was about $50 \%$ of the original weight. To determine this, the actual weight of the respective aggregate was repeatedly determined at certain time intervals (not fixed) during the erosion process.

The external and internal erosive strength of the aggregates $\left(E_{s}\right)$ is equivalent to the erosion forces applied to the surface of each soil aggregate layer, which were calculated from the frictional forces applied to the aggregate surface, using the mass of soil removed during a certain period of time of the application of a centrifugal force (Park and Smucker, 2005a) (Eq. 1)

$$
E_{S}=\frac{C_{F}}{\left[\frac{m\left(t_{n}\right)-m\left(t_{n-1}\right)}{t_{n}-t_{n-1}}\right]},
$$

where: $E_{s}=$ erosive strength of the aggregates $\left(\mathrm{N} \mathrm{g} \mathrm{min}{ }^{-1}\right)$; $C_{F}=$ centrifugal force $\left(\mathrm{g} \mathrm{mm} \mathrm{s}^{-2}\right) ; m\left(t_{n}\right)-m\left(t_{n-1}\right)=$ the mass of the soil aggregate (g) at time $t_{n}$ and $t_{n-1}(\mathrm{~min})$. 
The centrifugal force $\left(C_{F}\right)$ applied to the aggregates in the chambers was calculated following (Eq. 2):

$$
C_{F}=m(t)\left[R_{S K}+R_{S A E}-R_{a}(t)\right] \omega^{2},
$$

where: $C_{F}=$ centrifugal force $\left(\mathrm{g} \mathrm{mm} \mathrm{s}^{-2}\right) ; m(t)=$ mass $(\mathrm{g})$ at time $\mathrm{t}(\mathrm{min}) ; R_{S K}=$ radius of rotary shaker $(\mathrm{mm}) ; R_{S A E}=$ radius of erosion chamber $(\mathrm{mm}) ; R_{a}(t)=$ radius of aggregate $(\mathrm{mm})$, at time $t(\mathrm{~min}) ; \omega=$ angular velocity $\left(\right.$ radian $\left.\mathrm{s}^{-1}\right)$.

A chemical analysis was performed on the eroded material from the aggregate layers. The $\mathrm{pH}$ values were measured in a $0.01 \mathrm{M} \mathrm{CaCl}_{2}$ solution $\left(1: 2.5\right.$ soil: $\left.\mathrm{CaCl}_{2}\right)$ according to DIN ISO 11260 (2018). The content of total nitrogen and total carbon (mass \%) was determined using a CNS Element-Analyser (Vario EL III, Elementar, Langenselbold/Germany) according to DIN ISO 13878 (1998) and DIN ISO 10693 (1997).

A statistical analysis was carried out using the statistical software R version 3.5.1 (R Core Team, 2017). Based on graphical residual analysis, $\mathrm{pH}$-values, the $\mathrm{C}$ - and $\mathrm{N}$-content were assumed to be normally distributed and heteroscedastic due to the different lime application rates at the site. Based on these assumptions, an analysis of variances (One-Factor ANOVA) was performed (Snedecor and Cochran, 1996). All values were evaluated to compare the means of the factor levels treatment and plot for each site separately (Tukey-Test). The significance of the different tests was set at an a-Level of 5\%. Box-and-whisker plots (McGill et al., 1978) were chosen for graphical presentation, showing median (mid-line), 25th/75th percentile (lower/upper border of the box), 95th and 5th percentile (whiskers), 1st and 99th percentile (lower/upper line), outliers (dots) and means (squares).

\section{RESULTS AND DISCUSSION}

The erosive strength $\left(E_{s}\right)$ of the aggregates increased significantly from the exterior (ext.) to the interior (int.) layers $(\mathrm{p}<0.01)$ in all treatments (Fig. 1). The $E_{s}$ in both the ext. and int. layers of the aggregates significantly $(\mathrm{p}<0.05)$ decreased in the Lime1 treatment as compared to the control aggregates (Lime0). However, $E_{s}$ increased (but not significantly) in the int. layers of the aggregates from the Lime1.5 plots as compared to the control plots (Lime0).

The densities $(\rho)$ of the ext. layers decreased significantly for the air-dried aggregates from the lime treatments (Lime1 and Lime1.5) as compared to the control (Lime0) (Table 1). In comparison, the densities $(\rho)$ of the int. layers decreased (not significantly) for the air-dried aggregates from the lime treatments (Lime1 and Lime1.5) as compared to the control (Lime0).

Significant changes in both $\mathrm{pH}$ values and $\mathrm{C}$ and $\mathrm{N}$ contents as well as the $\mathrm{C}: \mathrm{N}$ ratio could not be detected. However, the $\mathrm{pH}$ values in the ext. layers were lower in aggregates from the Lime1.5 plots as compared to the aggregates from

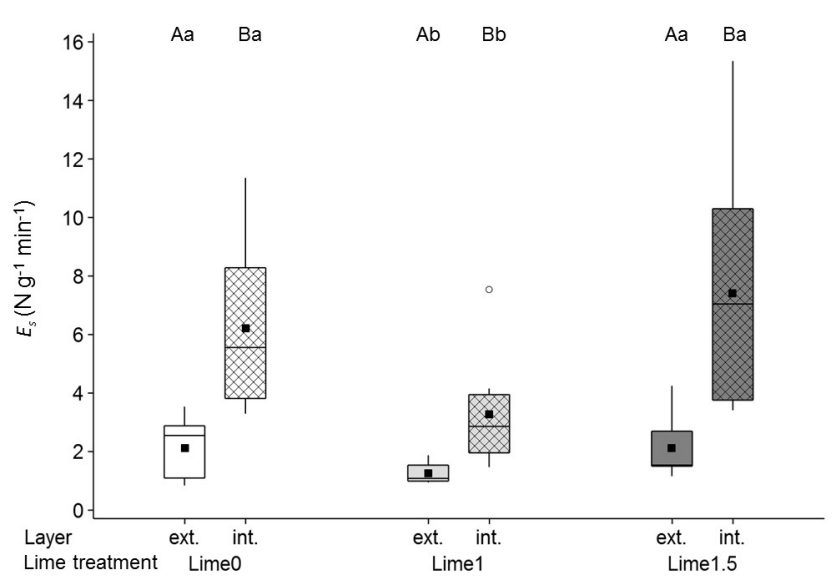

Fig. 1. The erosive strength $\left(E_{s}\right)$ of the exterior (ext.) and interior (int.) layers of the air-dried aggregates $(\varnothing \sim 16 \mathrm{~mm})$ obtained from the topsoil of different liming treatments (Lime0: control, Lime1: lime recommendation according to VDLUFA (2000a), Lime 1.5: lime recommendation according to VDLUFA (2000a) $\mathrm{x}$ 1.5) 32 months after lime application and incorporation $(n=10)$. Squares denote arithmetic means. The capital letters (A, B) identify statistically significant differences between the layers within an aggregate $(p \leq 0.01)$. Different lowercase letters $(a, b)$ identify significant differences among the liming treatments $(p<0.05)$.

Table 1. Density $(\rho)$ of the exterior (ext.) layer and the interior (int.) with the standard deviation (SD) of air-dried aggregates $(\varnothing$ $\sim 16 \mathrm{~mm}$ ) obtained from the topsoil of different liming treatments

\begin{tabular}{lcccc}
\hline \multirow{2}{*}{ Treatment } & \multicolumn{2}{c}{ Ext. layer of aggregates } & \multicolumn{2}{c}{ Int. layer of aggregates } \\
\cline { 2 - 5 } & $\rho\left(\mathrm{g} \mathrm{cm}^{-3}\right)$ & $\mathrm{SD}$ & $\rho\left(\mathrm{g} \mathrm{cm}^{-3}\right)$ & $\mathrm{SD}$ \\
\hline Lime0 & 1.64 & 0.09 & 1.67 & 0.07 \\
Lime1 & $1.41^{*}$ & 0.13 & 1.64 & 0.19 \\
Lime1.5 & $1.38^{*}$ & 0.31 & 1.62 & 0.08 \\
\hline
\end{tabular}

Lime0 - control, Lime1 - lime recommendation according to VDLUFA (2000a), Lime1.5 - lime recommendation according to VDLUFA (2000a) x 1.5, 32 months after lime application and incorporation $(\mathrm{n}=10), *$ indicate treatments significantly different from the control at $\mathrm{p}<0.05$.

the control (Lime0) (Table 2). Furthermore, the $\mathrm{pH}$ values increased in the int. layers of the air-dried aggregates from the Lime1 and Lime 1.5 plots as compared to the aggregates from the control (Lime0). The $\mathrm{pH}$ value is higher in the int. layer of aggregates as compared to the ext. layer of aggregates for the Lime1 and Lime1.5 treatments. The $\mathrm{pH}$ values are lower in the int. layer of aggregates from the control as compared to the ext. layer of the control (Lime 0 ). The total N-content decreased in both the ext. and int. layers of the air-dried aggregates from the lime treatments as compared to the control (Lime0) (Lime1.5 is unchanged). The content of $\mathrm{N}$ is higher in the int. layer of aggregates as compared to the ext. layer of aggregates for the Lime1 treatment. In addition, the content of $\mathrm{N}$ is lower in the int. layer of the aggregates as compared to the ext. layer of the control (Lime 0 ) and for the Lime1.5 treatment. The total C-content decreased in the ext. layers of the air-dried aggregates from lime treatments (Lime1 and Lime1.5) as compared to the control (Lime0) but increased in the int. layers of aggregates 
from the Lime1.5 treatments as compared to the control (Lime0). In addition, the $\mathrm{C}$ content is higher in the int. layer of aggregates as compared to the ext. layer of aggregates for the Lime1 treatment. In comparison, the content of $\mathrm{C}$ is lower in the int. layer of aggregates as compared to the ext. layer of the control (Lime0) and for the Lime1.5 treatment. The $\mathrm{C}: \mathrm{N}$ ratio is higher for the int. layers of the aggregates from the Lime1 treatment as compared to the ext. layers of the aggregates. In addition, the $\mathrm{C}: \mathrm{N}$ ratio is lower in int. layers of aggregates as compared to the ext. layers of the control (Lime1) and for the Lime1.5 treatment. However, the $\mathrm{C}: \mathrm{N}$ ratio is higher for the int. layers of the aggregates of Lime1.5 as compared to the control (Lime0).

Table 2. $\mathrm{pH}(-)$, total $\mathrm{N}$ (mass \%) and total C (mass \%) of the exterior (ext.) layers and the interior (int.) layers of air-dried aggregates $(\varnothing \sim 16 \mathrm{~mm})$ obtained from the topsoil of different liming treatments

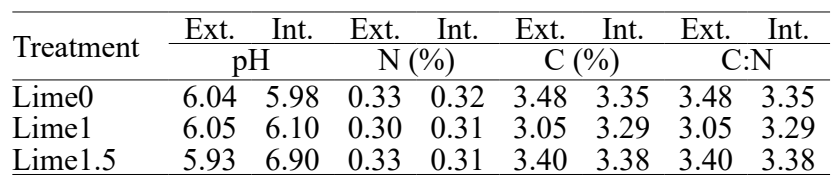

$\mathrm{n}=2$. Other explanations as in Table 1 .

The results show that the erosion strength $\left(E_{s}\right)$ of aggregates is not the only suitable parameter for assessing the stability of pore structure in tillage systems (Jasinska, 2006; Mordhorst, 2013), it is also applicable for the evaluation of the structure stabilizing effects of lime application on arable land. Park and Smucker (2005a) have already shown that the tensile strength of soil aggregates correlates well with their erosion strength and that the tensile strength of the aggregate is determined by the bonds within the aggregate between the particles Park and Smucker (2005a) recognized that the lowest intra-aggregate porosities occur in the interior of aggregates from conventionally tilled soils, this has consequences for the low accessibility of soil microorganisms to organic matter which is physically protected within soil aggregates. In comparison, this study determined a higher $E_{s}$ value with a simultaneous decrease in the density of the int. layers for the aggregates of the limed plots. The surfaces of aggregates are microbial hot spots (Kuzyakov and Blagodatskaya, 2015), and the microbial activity depends on the actual $\mathrm{pH}$ in the soil and may be stimulated by a decrease in the $\mathrm{pH}$ value after the addition of lime (Muñoz et al., 2012). The higher $E_{s}$ value of the exterior and interior layers of aggregates as well as the overall increase in aggregate stability may be influenced by repeated swelling and shrinkage processes (Bronswijk and Evers-Vermeer, 1990) which occur preferentially in the exterior aggregate layer in the vicinity of the already existing cracks. Repeated shrinkage and swelling causes soil aggregation due to the rearrangement of soil particles as a result of the stress of increasing soil-water suction. This is particularly the case when layered silicates of the 2:1 type are altered by changes in water content - they swell and increase their volume. This means that these soils expand when they are wet and contract when they dry out (Kay, 1990). Gradients of microbial activity and the expression of root density within the aggregates also influence aggregate stability through the secretion of extracellular polysaccharides or through the activity of fungal hyphae, whereby aggregates become glued together and contribute to an increase in the stability of the soil (Totsche et al., 2018).

Similar to the findings of Urbanek et al. (2014), most aggregates in our study were found to have a lower aggregate density in the ext. layers than in the int. layers. Moreover, both the densities of the ext. and int. layers were found to be lowest in aggregates from the limed plots, the particle rearrangement in the porous "card-house"-structure during the flocculation and agglomeration processes after lime application resulted in an enhanced intra-aggregate pore accessibility (Park and Smucker, 2005b; Smucker et $a l ., 2007)$. Due to the short time period of our experiment, it is difficult to arrive at conclusions which may be applied in the long-term. The lower aggregate density which also increased the aggregate stability of the aggregates of the limed plots, however, shows that such loosely bound aggregates can result in the enhancement of cation exchange processes (Hartmann et al., 1998), as well as in the increased diffusion of soil solution components from the aggregate surfaces into the aggregate interior (Becher, 1991), where they can enhance the formation of e.g. organo-mineral complexes that further increase aggregate stability (Peth $e t$ al., 2008; Smucker et al., 2007). On the other hand, the low erosive strength of the aggregate exterior layers indicates the high degree of sensitivity of the aggregate exterior to abrasive forces, as they may occur during transport through wind or water erosion. As a consequence, organic matter stored in the exterior layers of aggregates is predominantly exposed to mineralization upon exterior aggregate deformation (Mordhorst, 2013). This type of nutrient release can lead to the increased mineralization of organic matter, and therefore to increased soil fertility, as more nutrients are available in the soil. However, in view of increasing levels of greenhouse gases and ongoing climate change, the excessive mineralization of soil organic matter on agricultural land should be avoided. In general, an increase in $\mathrm{pH}$ due to the application of lime and the induced microbial decomposition which results are therefore necessary on agricultural land to ensure the mineralization of $\mathrm{C}$ and $\mathrm{N}$ (Edemeades et al., 1981).

As a consequence of the factors mentioned above, liming indirectly improves the transport of nitrogen and the storage of carbon in soils through the rearrangement of particles resulting in increased aggregate strength and soil stability. Our results have shown that a higher degree of aggregate stability promotes the development of a stronger soil structure, which helps to ameliorate homogenization and kneading under the stress of mechanical impact (for 
example, during tillage). Further investigation will be necessary to investigate different textures (sand, loam) and soil types as well as their parent rocks. In addition, different soil management systems (reduced tillage) should be considered in order to determine over what period of time the erosion stability effect will be retained and to transfer the results from field trials to a broader scale.

\section{CONCLUSIONS}

1. Lower bulk densities were detected on limed plots, which may indicate a reorientation of particles.

2. Liming significantly increased the erosive strength of aggregates and may improve the accessibility of pores and particle surfaces within the aggregates.

3. The study presented should be supported by further measurements to demonstrate that liming has the potential to make a meaningful contribution to the reduction of greenhouse gases by improving the fixation of carbon and nitrogen in aggregates.

\section{ACKNOWLEDGEMENTS}

We wish to express our sincere gratitude to the farmer involved in the study for his cooperation which included permission to take samples in his field.

\section{REFERENCES}

Becher H.H., 1991. Über die Aggregatdichte und deren mögliche Auswirkung auf den Bodenlösungstransport. Z. Pflanzenernaehr. Bodenk., 154(1), 3-8, https://doi.org/10.1002/ jpln.19911540103

Bronick J. and Lal R., 2005. Soil structure and management: A review. Geoderma, 124(1-2), 3-22, https://doi.org/10.1016/j. geoderma.2004.03.005

Bronswijk J.J.B. and Evers-Vermeer J.J., 1990. Shrinkage of Dutch clay soil aggregates. NJAS, 38(2), 175-194, https:// doi.org/10.18174/njas.v38i2.16603

DIN ISO 10693, 1997. Soil quality - Determination of carbonate content - Volumetric method.

DIN ISO 11260, 2018. Soil quality - Determination of effective cation exchange capacity and base saturation level using barium chloride solution.

DIN ISO 13878, 1998. Soil quality - Determination of total nitrogen content by dry combustion ("elemental analysis").

Edemeades D.C., Judd M., and Sarathchandra S.U., 1981. The effect of lime on nitrogen mineralization as measured by grass growth. Plant Soil, 60, 177-186, https://doi. org/10.1007/BF02374102

Ferreira T.R., Pires L.F., Wildenschild D., Brinatti A.M., Borges J.A.R., Auler A.C., and dos Reis A.M.H., 2019. Lime application effects on soil aggregate properties: Use of the mean weight diameter and synchrotron-based X-ray $\mu \mathrm{CT}$ techniques. Geoderma, 338, 585-596, https://doi. org/10.1016/j.geoderma.2018.10.035

Frank T., Zimmermann I., and Horn R., 2020. Lime application in marshlands of Northern Germany-Influence of liming on the physicochemical and hydraulic properties of clayey soils. Soil Till. Res., 204, 104730, https://doi.org/10.1016/j. still.2020.104730
Hartmann A., Gräsle W., and Horn R., 1998. Cation exchange processes in structured soils at various hydraulic properties. Soil Till. Res., 47(1-2), 67-72, https://doi.org/10.1016/ S0167-1987(98)00074-9

Haynes R.J. and Naidu R., 1998. Influence of lime, fertilizer and manure applications on soil organic matter content and soil physical conditions: A review. Nutr. Cycling Agroecosyst., 51, 123-137, https://doi.org/10.1023/A:1009738307837

Holland J.E., Bennett A.E., Newton A.C., White P.J., McKenzie B.M., George T.S., Pakeman R.J., Bailey J.S., Fornara D.A., and Hayes R.C., 2018. Liming impacts on soils, crops and biodiversity in the UK: A review. Sci. Total Environ., 610-611, 316-332, https://doi.org/10.1016/j. scitotenv.2017.08.020

Horn R., 1990. Aggregate characterization as compared to soil bulk properties. Soil Till. Res., 17(3-4), 265-289, https:// doi.org/10.1016/0167-1987(90)90041-B

Horn R. and Fleige H., 2003. A method for assessing the impact of load on mechanical stability and on physical properties of soils. Soil Till. Res., 73(1-2), 89-99, https://doi. org/10.1016/S0167-1987(03)00102-8

IUSS Working Group WRB, 2014. World Reference Base for Soil Resources 2014, Update 2015: International soil classification system for naming soils and creating legends for soil maps. World Soil Resources Reports No. 106. FAO, Rome (106).

Jasinska E., 2006. Management effects on carbon distribution in soil aggregates and its consequences on water repellency and mechanical strength 71. Schriftenreihe; Institut für Pflanzenernährung und Bodenkunde, Kiel.

Jastrow J.D., 1996. Soil aggregate formation and the accrual of particulate and mineral-associated organic matter. Soil Biol. Biochem., 28(4-5), 665-676, https://doi. org/10.1016/0038-0717(95)00159-X

John B., Yamashita T., Ludwig B., and Flessa H., 2005. Storage of organic carbon in aggregate and density fractions of silty soils under different types of land use. Geoderma, 128(1-2), 63-79, https://doi.org/10.1016/j.geoderma.2004.12.013

Kay B.D., 1990. Rates of change of soil structure under different cropping systems. Advances in Soil Science, 12, 1-52, https:// doi.org/10.1007/978-1-4612-3316-9_1

Kuzyakov Y. and Blagodatskaya E., 2015. Microbial hotspots and hot moments in soil: Concept \& review. Soil Biol. Biochem., 83, 184-199, https://doi.org/10.1016/j.soilbio.2015.01.025

McGill R., Tukey J.W., and Larsen W.A., 1978. Variations of box plots. Am. Stat., 32(1), 12, https://doi.org/10.2307/2683468

Mordhorst A., 2013. Soil Structure-Carbon Relations of Differently Textured and Managed Arable Soils Subjected to Mechanical Loading. Schriftenreihe, Institut für Pflanzenernährung und Bodenkunde 99. Schriftenreihe, Instiut für Pflanzenernährung und Bodenkunde, Kiel.

Mordhorst A., Peth S., and Horn R., 2013. Degradation effects on organic carbon and mechanical strength within aggregates from a Stagnic Luvisol depending on tillage intensity. In: Soil degradation. Advances in geoecology 42 (Eds J. Krümmelbein, R. Horn, M. Pagliai). Catena Verlag GmbH, Reiskirchen.

Muneer M. and Oades J.M., 1989. The role of Ca-organic interactions in soil aggregate stability. III. Mechanisms and models. Aust. J. Soil Res., 27, 411-423, https://doi.org/10.1071/ SR9890411 
Muñoz C., Torres P., Alvear M., and Zagal E., 2012. Physical protection of $\mathrm{C}$ and greenhouse gas emissions provided by soil macroaggregates from a Chilean cultivated volcanic soil. Acta Agric. Scand. B - Soil Plant Sci., 62(8), 739-748, https://doi.org/10.1080/09064710.2012.700317

Naveed M., Arthur E., de Jonge L.W., Tuller M., and Moldrup P., 2014. Pore structure of natural and regenerated soil aggregates: An X-Ray computed tomography analysis. Soil Sci. Soc. Am. J., 78(2), 377, https://doi. org/10.2136/sssaj2013.06.0216

Park E.J. and Smucker A.J.M., 2005a. Erosive strengths of concentric regions within soil macroaggregates. Soil Sci. Soc. Am. J., 69(6), 1912-1921, https://doi.org/10.2136/sssaj2004.0400

Park E.J. and Smucker A.J.M., 2005b. Saturated hydraulic conductivity and porosity within macroaggregates modified by tillage. Soil Sci. Soc. Am. J., 69(1), 38, https://doi. org/10.2136/sssaj2005.0038

Park E.-J. and Smucker A.J.M., 2005c. Dynamics of carbon sequestered in concentric layers of soil macroaggregates. The Korean J. Ecol., 28(4), 181-188, https://doi. org/10.5141/JEFB.2005.28.4.181

Peth S., Horn R., Beckmann F., Donath T., Fischer J., and Smucker A.J.M., 2008. Three-dimensional quantification of intra-aggregate pore-space features using synchrotronradiation-based microtomography. Soil Sci. Soc. Am. J., 72(4), 897-907, https://doi.org/10.2136/sssaj2007.0130

R Core Team, 2017. R Studio version 3.5.1.

Santos D., Smucker A.J.M., Murphy S.L.S., Taubner H., and Horn R., 1997. Uniform separation of concentric surface layers from soil aggregates. Soil Sci. Soc. Am. J., 61(3), 720, https://doi.org/10.2136/sssaj1997.03615995006100030003x

Schroeder G., 1968. Landwirtschaftlicher Wasserbau, Vierte umgearbeitete Auflage ed. Handbibliothek für Bauingenieure, Ein Hand- und Nachschlagebuch für Studium und Praxis. Springer, Berlin, Heidelberg.
Six J., Elliott E.T., and Paustian K., 2000. Soil macroaggregate turnover and microaggregate formation: a mechanism for C sequestration under no-tillage agriculture. Soil Biol. Biochem., 32, 2099-2103, https://doi.org/10.1016/ S0038-0717(00)00179-6

Smucker A.J.M., Park E.-J., Dorner J., and Horn R., 2007. Soil micropore development and contributions to soluble carbon transport within macroaggregates. Vadose Zone J., 6(2), 282, https://doi.org/10.2136/vzj2007.0031

Snedecor G.W. and Cochran W.G., 1996. Statistical methods, 8th ed. Iowa State University Press, Iowa.

Tisdall J.M. and Oades J.M., 1982. Organic matter and waterstable aggregates in soils. J. Soil Sci., 33, 141-163, https:// doi.org/10.1111/j.1365-2389.1982.tb01755.x

Totsche K.U., Amelung W., Gerzabek M.H., Guggenberger G., Klumpp E., Knief C., Lehndorff E., Mikutta R., Peth S., Prechtel A., Ray N., and Kögel-Knabner I., 2018. Microaggregates in soils. J. Plant Nutr. Soil Sci., 35, 117, https:// doi.org/10.1002/jpln.201600451

Urbanek E., Horn R., and Smucker A.J.M., 2014. Tensile and erosive strength of soil macro-aggregates from soils under different management system. J. Hydrol. Hydromech., 62(4), 324-333, https://doi.org/10.2478/johh-2014-0034

VDLUFA, 2000. Bestimmung des Kalkbedarfs von Acker - und Grünlandböden. Verband Deutscher Landwirtschaftlicher Untersuchungs - und Forschungsanstalten.

Wang Y., Cui Y.-J., Tang A.M., Benahmed N., and Duc M., 2017. Effects of aggregate size on the compressibility and air permeability of lime-treated fine-grained soil. Eng. Geol., 228, 167-172, https://doi.org/10.1016/j.enggeo.2017.08.005

Wiesmeier M., Steffens M., Mueller C.W., KölblA., ReszkowskaA., Peth S., Horn R., and Kögel-Knabner I., 2012. Aggregate stability and physical protection of soil organic carbon in semiarid steppe soils. Eur. J. Soil Sci., 63(1), 22-31, https://doi. org/10.1111/j.1365-2389.2011.01418.x 